\title{
SPACE Analysis as a Tool for Internal Development Factors Measurement within Companies
}

\author{
Jelena BOROCKI, Mladen RADIŠIĆ, Ivan ŠTEFANIĆ
}

\begin{abstract}
This paper presents the analysis of internal development factors in manufacturing and services companies from the selected SEE countries, by using strategic planning model - modified SPACE (Strategic Position and ACtion Evaluation) analysis. The advantage of the SPACE model, as A. Rowe defined it, is a possibility to apply it with the excellent results when analysing companies in highly developed countries as well as in developing countries. The structure of the differences among manufacturing and service companies was performed using canonical discriminative analysis. The most significant development factors were chosen from the modified SPACE strategic planning model and correlated with companies' internal development factors. Research results indicate that service companies perceive internal development factors more importantly for the market successes than manufacturing ones. At the same time, they experienced more aggressive strategic posture.
\end{abstract}

Keywords: development; manufacturing companies; service companies; SPACE model; strategic planning

\section{INTRODUCTION}

Following the development trends from the previous years (even decades), very important changes within all spheres of society may be noticed, which have had an intensive impact to the business operation changes. One of them is definitely globalization happening across the board and the speed of technical and technological developments has entirely changed the business environment [8]. When operating in such conditions, companies are changing under different influences coming from the external environment and they are trying, at the same time, to ensure continuous development of all important internal elements. Company development relies on key qualitative changes within a company, qualitative expansion, constant improvements, and innovation of products, services, structure and/or technology, including quantitative operation increase. This is a very complex interaction that often requires the creation of new resource combinations at company or design of new objectives, and in some exceptional situations, even company mission change.

The key moment of any company's strengths lies within essential and sustainable continuous development [13]. It is very incorrect to observe company development only through product and/or service development prism. Product/service development is only one segment resulting from a company's innovation process. Through innovation, as a by-product of investment in research and development, every company creates its competitive advantage [14]. Company development as a whole includes the development of all areas of operation: organisational structure development, technology development, human resources development, operations development, etc. It includes an integral development procedure regarding all company processes. Therefore, in order to understand an appropriate strategic positioning of a company, one must select the most important factors that influence business processes. Later on, those factors and their mutual relations have to be further analysed.

Each of the functions within a company is evaluated through certain operation quality measures. Therefore, development level of some of the functions could be actually seen through the levels of these key indicators.
Company development planning and organisation include the definition and implementation of decisions on development policies, strategies, objectives, plans, and development programs, directing company activity, fully in line with company vision and mission. Development often requires changes of key operation aspects, change in the essence of operational system, thus, the creation of resistance is necessary - the development results in less certain outcome, it gets more complex, and it is more difficult to control it, in relation to company growth (which is a necessary but not sufficient condition for more successful company operation in the future). As claimed by some authors e.g. Šikula [28], development in transition economies and their comparison with economic development in EU countries prove that steadiness of growth is indispensable condition for ensuring permanent growth at a pace sufficient to resolve convergence task.

This paper investigates possible differences between manufacturing and service companies in terms of the key factors determining the company's development by applying the modified SPACE analysis, within the domain of the significance of these factors. The identified similarities and differences result from the implemented research.

\section{THEORETICAL BACKGROUND}

The distinctive differences between manufacturing and service companies which used to exist have now faded. Nowadays, information technologies, new knowledge, innovation activities, and original strategies for becoming competitive, play an important role not only for service but also for manufacturing companies. It might be considered nowadays that standpoint claiming that service industries are technologically backward could be misleading. Numerous empirical evidences show that technology does play a role in services, whereby a large amount of information technology investment is used by services [27].

Manufacturing companies traditionally correlate their strategic development with the amount of money spent in R\&D activities. They are more formalized in their development processes $[11,15]$, which is not a case for 
service companies. Product innovation and process innovation, through which new products/services are developed, are associated in most of the cases [20]. In their work, Popescu and Tăchiciu [19] state that innovation in the services sector is generally brought by investment in acquisition of new skills, new organizational structures, new ways of co-operation, creation of new enterprises and relations with customers and suppliers. Comparing to manufacturing companies, service companies are faced with problems how to make entry barriers higher; how to better protect intellectual properties and make it harder to copy service; and how to easily measure performance indicators (productivity, quality, efficiency, customer satisfaction) [9], which are very important, knowing that service development and process development are divergent [18]. But services are no longer add-ons to products provided by a certain type of companies. Thus, many authors consider that services generate huge amount of R\&D [7] and have become an inherent part of all goods manufactured and can occur before and during manufacturing, as a part of selling, during consumption, and after consumption and usage [26]. Rant [23] advocates that many companies sell products and services at the same time and, in many cases, the distinction between a manufactured product and a service is not obvious. Today, many manufacturing companies are faced with a process of servitization. It is not an easy process, mostly because in a service-centred environment, firms should adopt a culture that places a high emphasis on customer satisfaction; they should have well educated and trained sales people as well as supporting organizational structure and culture [16].

When launching new services/products on the market, both manufacturing and service companies must apply particular strategies. It is equally important to both that, in the process of creating respective strategies, an efficient strategic planning model is available.

\section{MATERIALS AND METHODS 3.1 Methodology}

Use of various management tools in the researches of Bain \& Company [1] from the previous few years indicates that the strategic planning has got the best results through measured level of user satisfaction and frequency of tools use. Even today, within the innovative economy, the strategic planning has found its place - but not without some significant changes in its essence. Strategy, as a result of strategic planning process, is another internal factor that is shown to have an impact on innovation $[21,10]$ and thus on a future development level of company. Though the strategic planning by itself may not foresee the direction of the development of the market, i.e. all vital components of the external environment impacting the company's competitiveness with high certainty, strategic innovations and strategic plan improvements, and the methods used in the strategic planning need to be a basis of the strategy of a company that wants to survive in the time of complex business climate. Various models of operation analysis are used in the strategic planning, including SWOT (Strengths Weaknesses Opportunities Threats) and PEST (Political Economic Social Technological) analysis, SPACE analysis, Portfolio methods, BSC (Balanced Scorecard), etc., which almost have the same objective - to analyse the current situation at the company and its environment as best as possible and to propose the strategies for increasing company competitiveness. Therefore, it is very important to know its current strategic position, by applying one of the strategic planning models. Strategic Position and Action Evaluation model - SPACE [24, 3] is a model by the application of which it is possible to define not only strategic position but also the most critical factors and indicators that could have a great impact on all development processes at company or its competitiveness level. The SPACE model is a developed version of the BCG (Boston Consulting Group) matrix. This model includes two internal (Financial strength - FS and Competitive advantage - CA) and two external dimensions (Environmental stability - ES and Industry strength - IS). The sum of CA and IS (resp. FS and ES) values will give the final $\mathrm{x}$ (resp. $\mathrm{y}$ ) value of one of the organization's suggested strategy postures: aggressive, conservative, competitive, or defensive. The absolute value and direction of resulting vector is also important in the process of planning possible directions of company's development strategy (Fig. 1).

Applying modified SPACE method should result in company's increase in capability to think and act in a strategic manner, and, thus, to be competitive and innovative. Some authors [25, 6, 22, 2, 29] claim that modification of original SPACE method, is useful and could rely on different methods, e.g. Fuzzy logic, AHP (Analytic Hierarchy Process) method, etc. Similarly, the used methodology in this paper is also based on the modification of original SPACE method, as explained below.

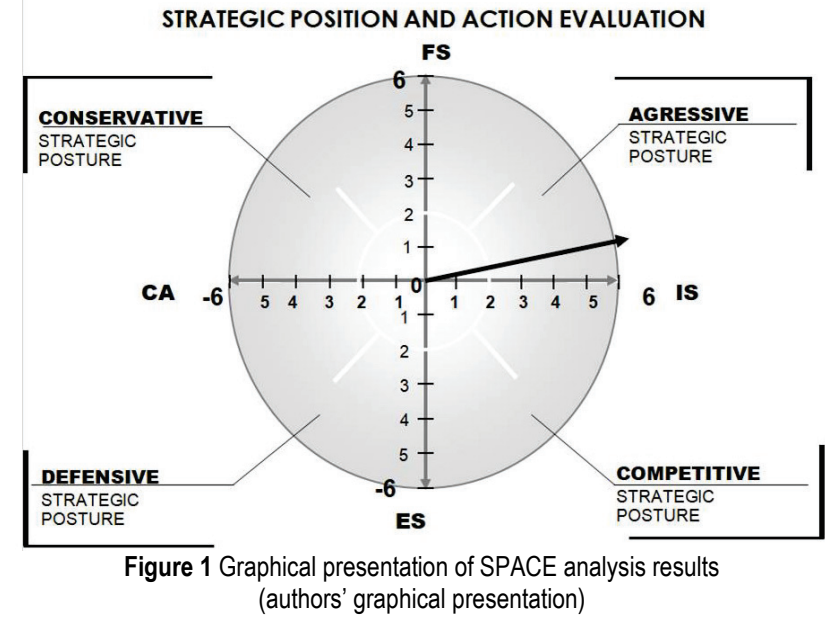

The first modification is expansion of number of factors (to reach 80 factors in total, nearly four times more than the original SPACE method) in each of four SPACE method basic dimensions. With this expansion, more accurate statistical processing of internal development factors within companies is possible. Within second modification, the need for in-depth classification of certain factors that are impossible to be measured without prior measuring of their integral parts is recognized. This enables quantitative measuring for each and every factor in modified SPACE method. In its original form, SPACE method assesses only the value of factors by using Likert scale. Therefore, third modification brings additional 
Likert scale measurement for perception of significance for each factor. Based on this, the fourth and most important modification determines a set of critical factors that predominantly influence company's strategic posture. Those modifications introduce the possibility of simulation where a company can change values of the most critical factors, understand and improve its strategic position. A similar methodology was used by Borocki et al. [5]. In that paper, authors have observed the factors that influence companies' external environment, while this paper focuses on internal development factors within companies on the same data sample. Taking into account that a company can influence directly two major internal dimensions of SPACE analysis, the authors have selected the most significant factors belonging to FS and CA dimensions, as explained in section 4 .

When it comes to proper selection of relevant internal development factors, methodology is focused on products/services, operation technology development and human resources as basic, key elements of the business functioning (regardless of whether it is service or manufacturing company). Griffin [11], Hughes and Wood [12] and Sirilli and Evangelista [27] indicate that there are numerous similarities in the process of new service and new product development, but there are also certain differences: internal organizational factors are more important in the process of new service development than in the process of new product development [17]. Therefore, the selection of that factor - product/service development - is a logical choice since the most successful global companies constantly introduce new products and services. Taking into consideration the importance of technology for both service and manufacturing companies, the second selected factor for comparative analysis is operation technology development. Human resource development is especially important for service companies, knowing that human resources are increasingly recognized as a key competitive element of firms' innovative strategies [27]. Since the majority of new product development ideas are implemented within company by its staff, the human resource development factor is equally important for manufacturing company development. This was the reason for the selection of exactly those factors of company development which will point out their lower or higher significance for the selected company competitiveness factors. Since it is impossible to measure those selected company development factors (which is the problem with the majority of the factors which should determine the success of the company operation), their value was assessed in terms of: investment continuity and investment level (where it has been considered that a factor has reached high value if the continuing development has been achieved and the level of investment in that factor completely covers the development needs).

This study brings the new approach in observing the strategic planning implementation possibilities, since it focuses on (i) a comprehensive outreach of numerous factors of modified SPACE, (ii) observes the most important relevant internal development factors within companies and (iii) investigates conceptual differences between manufacturing and services companies (covering a three digit sample) from the selected emerging markets.
In this way, similar research studies conducted elsewhere have been given a new perspective.

\subsection{Explanation of the Sample}

The research sample consists of 51 manufacturing and 75 service companies (different in their size, legal form of organization, industry sector, location, and ownership are selected) coming from three regional SEE countries: Serbia, Bosnia and Herzegovina and Montenegro. The reason for selecting the sample was twofold: to cover more than one regional emerging market and to conduct an interview with senior management in tête-à-tête fashion over the period of three years. All three regional SEE countries are characterized by frequent reforms of the economic and societal legislations, continual internal and external financial turmoil, high level of country risk (i.e. political risk, economic risk and financial risk), changes of the credit rating, fluctuation of the foreign currency exchange rates, etc. Although different in some aspects, all those countries have a common denominator being countries in the EU integration process. Also, they have emerging economies and are seen as an interesting investment destination. The questionnaire covers 80 hierarchical structural factors and/or indicators which are individually evaluated in terms of their level of significance and value. That includes various operation areas, so it is necessary to complete the questionnaire by several employees from various areas - organizational units of the company, whose competences, knowledge, and experience in certain fields are used to get as objective evaluation as possible i.e. significance of a factor and/or indicator from the questionnaire [4]. In the final sample of the entities, after the exclusion of the companies and factors with more than $5 \%$ of the missing answers (due to incomplete questionnaire), 116 companies are kept in further analysis.

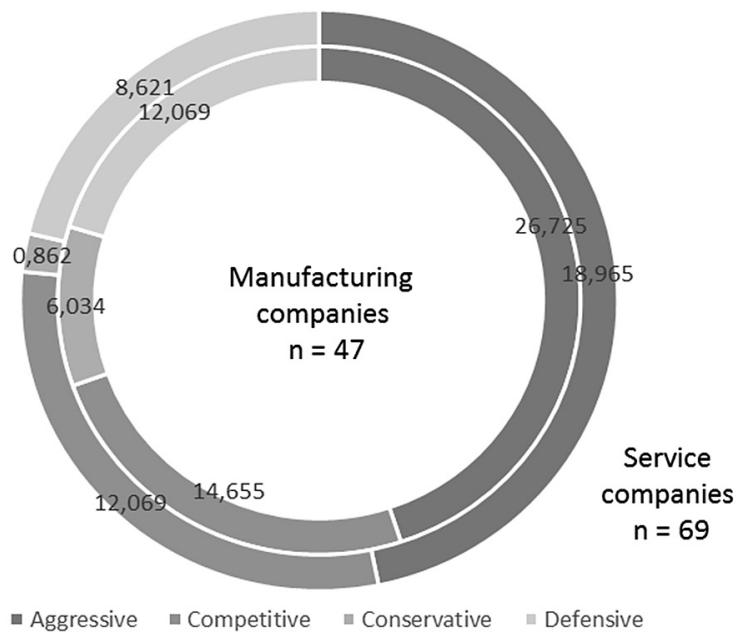

Figure 2 Sample structure by company size

Research sample covered $40.5 \%$ of manufacturing and $59.5 \%$ of services companies. Small and medium enterprises are significantly represented within the sample structure, at around $27 \%$ for manufacturing companies and $50 \%$ for service companies (Fig. 2). Most of the manufacturing companies from the research sample are Ltd. $-20.7 \%$, as well as service companies $-25.8 \%$. Since 
modified SPACE method is used in this research for defining company's strategic position, the structure of the sample is given in Fig. 3.

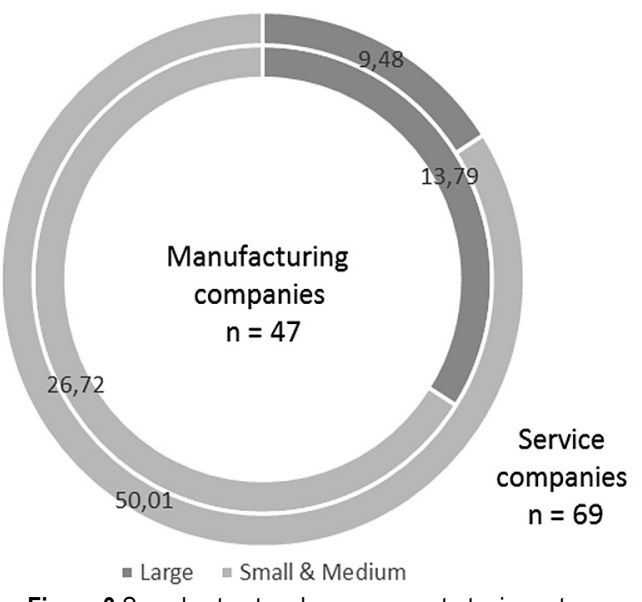

Figure 3 Sample structure by company strategic posture

\section{RESULTS}

By using the Likert scale, each factor of the modified SPACE analysis is assessed in view of its significance and values. T-tests for independent samples determine the statistical significance of the difference of the average assessments of the selected factors (within the significance domain) between the manufacturing and service companies [5].

In the course of the analysis, the grouping (independent) variable included the activity (manufacturing/service) while the set of the variables included the scores at the selected development factors from modified SPACE analysis. It is presented in Tab. 1. Levene test is used to test and verify that this equal variance assumption is reasonable.

Statistically significant difference between the manufacturing and service companies in terms of the significance of development factors (level of factor's importance for observer) is obtained only for the factors Product/service quality and Operation technology development. T-tests are significant at the level of $p<0.05$. Based on the values of arithmetic means of these factors, it may be seen that the manufacturing companies, considering their development, place higher significance to these factors. The same analysis, for the same selected factors from modified SPACE analysis and internal development factors, was made in a value domain. Statistically significant difference is obtained only for the factor Product/service quality (Borocki et al. [5]).

Table 1 Results of t-test ( ${ }^{*}$-test for non-homogenous variances) - significance domain

\begin{tabular}{|c|c|c|c|c|c|c|c|}
\hline Factors selected from the modified SPACE analysis & Levene $F$ & $P$ & $t$ & $d f$ & $p$ & $\begin{array}{c}\text { Mean } \\
\text { (manuf.) }\end{array}$ & $\begin{array}{c}\text { Mean } \\
\text { (services) }\end{array}$ \\
\hline Market share & .180 & .672 & -.188 & 114 & .851 & 2.9149 & 2.9478 \\
\hline Product/service quality & 5.395 & .022 & $2.320 *$ & 114 & .022 & 3.6064 & 3.3087 \\
\hline Average product/service life cycle stages & .038 & .846 & 1.363 & 109 & .176 & 2.6778 & 2.4212 \\
\hline Completeness of production program/service program & 2.916 & .090 & 1.279 & 113 & .204 & 3.0543 & 2.8420 \\
\hline Uniqueness (originality) of products/services & 1.775 & .185 & 1.536 & 114 & .127 & 3.0000 & 2.6826 \\
\hline Capability of introducing new products/services & .358 & .551 & .801 & 114 & .425 & 3.1277 & 2.9783 \\
\hline Available know-how & .967 & .327 & 1.876 & 114 & .063 & 3.3191 & 2.9942 \\
\hline Use of capacities in relation to major competitors & .641 & .425 & .683 & 114 & .496 & 3.0213 & 2.8986 \\
\hline Product/service development & .015 & .903 & .708 & 113 & .480 & 3.0745 & 2.9426 \\
\hline Operation technology development & 2.757 & .100 & 2.254 & 113 & .026 & 3.2660 & 2.8529 \\
\hline Human resources development & 1.605 & .208 & 1.476 & 114 & .143 & 3.3936 & 3.1449 \\
\hline Harmonization of org. structure with changes in the environ./company & 7.883 & .006 & 1.590 & 114 & .115 & 3.0426 & 2.7725 \\
\hline Timely taking of corrective actions & .139 & .710 & -.586 & 113 & .559 & 3.1383 & 3.2250 \\
\hline Flexibility in relation to client requirements & .780 & .379 & .589 & 114 & .557 & 3.3830 & 3.3014 \\
\hline Return of investments & .537 & .465 & .929 & 114 & .355 & 3.2447 & 3.0942 \\
\hline Level of cash inflow in terms of self-finance & .272 & .603 & .313 & 114 & .755 & 3.0638 & 3.0058 \\
\hline Placement of interim cash surpluses & .219 & .641 & -.594 & 114 & .554 & 2.2766 & 2.4130 \\
\hline
\end{tabular}

\subsection{Analysis of Relations between Modified SPACE Model Factors and Internal Development Factors}

This relation has been checked using Pearson's coefficient of linear correlation especially on the subsamples of the manufacturing and service companies.

Results of the correlation of the selected factors of modified SPACE analysis with the internal development factors of any company (product/service development, human resources development, and operation technology development), on the sub-sample of the manufacturing companies indicate that the manufacturing companies perceive that the factors: Product/service quality, Product/service uniqueness (originality), Capability of introducing new products/services, Use of capacities in relation to main competitors, Harmonisation of organisational structure with changes in the environment/company, Timeliness of taking corrective actions, and Flexibility in relation to client requirements, have got positive correlation with the internal development factors Product/service development, Operating technology development, and Human resources development. The highest values of Pirson's correlation coefficients (significant positive correlation of high intensity, $r>$.7) are noticed between the factors: Product uniqueness (originality) and Capability of introducing new products, and Product/service development factors. There is negative correlation between the factors of modified SPACE analysis: Level of cash inflow in terms of selffinance and internal development factors: Development of operating technology, human resources development, and products/services development. Also, between market 
share and Product/service development is negative correlation.

Observing the results on the sub-sample of service companies, it is seen that the situation is somewhat different than with the manufacturing companies. Here, the group of the factors which have got significant positive correlation of moderate intensity with the key internal development factors: product/service development, operating technology development, and human resources development, covers virtually all selected factors of modified SPACE analysis, except the factor: Placement of interim cash surpluses which express positive correlation only with internal development factor: Operational technology development. Moderate relations are between the factors: Uniqueness (originality) of products/services and Human resource development; Capability of introducing new products/services and Available knowhow with internal development factor Operational technology development and Product/service development. The highest correlation is between Product/service development and Operational technology development. All other correlations between selected factors of modified SPACE analysis and internal development factors are positive, with low intensity. There are no negative correlations.

Table 2 Correlation matrix of the selected development factors in the scales of the modified SPACE model within the group of manufacturing companies $(N=47$ ) (significance domain)

\begin{tabular}{|c|c|c|c|c|c|c|}
\hline \multirow[t]{2}{*}{ Selected factors of modified SPACE analysis } & \multicolumn{2}{|c|}{$\begin{array}{c}\text { Product/service } \\
\text { development }\end{array}$} & \multicolumn{2}{|c|}{$\begin{array}{c}\text { Operation technology } \\
\text { development }\end{array}$} & \multicolumn{2}{|c|}{$\begin{array}{c}\text { Human resources } \\
\text { development }\end{array}$} \\
\hline & $r$ & $p$ & $r$ & $p$ & $r$ & $p$ \\
\hline Market share & -.090 & .547 & .104 & .488 & .061 & .683 \\
\hline Product/service quality & .599 & .000 & .576 & .000 & .447 & .002 \\
\hline Average product/service life cycle stages & .088 & .565 & .055 & .720 & .090 & .557 \\
\hline Completeness of production/service program & .235 & .117 & .322 & .029 & .123 & .416 \\
\hline Uniqueness (originality) of products/services & .757 & .000 & .549 & .000 & .422 & .003 \\
\hline Capability of introducing new product/services & .730 & .000 & .635 & .000 & .490 & .000 \\
\hline Available know-how & .566 & .000 & .368 & .011 & .219 & .139 \\
\hline Use of capacities in relation to major competitors & .373 & .010 & .404 & .005 & .502 & .000 \\
\hline $\begin{array}{l}\text { Harmonisation of org. structure with changes in the } \\
\text { environment/company }\end{array}$ & .349 & .016 & .393 & .006 & .373 & .010 \\
\hline Timely taking of corrective action & .399 & .005 & .368 & .011 & .627 & .000 \\
\hline Flexibility in relation to client requirements & .424 & .003 & .429 & .003 & .531 & .000 \\
\hline Return of investments & .163 & .274 & .290 & .048 & .315 & .031 \\
\hline Level of cash inflow in terms of self-finance & -.163 & .274 & -.140 & .349 & -.114 & .445 \\
\hline Placement of interim cash surpluses & .151 & .310 & .224 & .130 & .234 & .114 \\
\hline Product/service development & 1 & & .720 & .000 & .603 & .000 \\
\hline Operation technology development & .720 & .000 & 1 & & .576 & .000 \\
\hline Human resource development & .603 & .000 & .576 & .000 & 1 & \\
\hline
\end{tabular}

$r$ - Pearson's coefficient of correlation; $p$ - Level of significance

Table 3 Correlation matrix of the selected internal development factors in the scales of the modified SPACE model within the group of service companies $(N=69)$ (significance domain)

Selected factors of modified SPACE analysis

Market share

Product/service quality

Average product/service life cycle stages

Completeness of product/service program programme

Uniqueness (originality) of products/services

Capability of introducing new products/services

Available know-how

Use of capacities in relation to major competitors

Harmonization of org. structure with changes in the

environment/company

Timely taking of corrective action

Flexibility in relation to client requirements

Return of investments

Level of cash inflow in terms of self-finance

Placement of interim cash surpluses

Product/service development

Operation technology development

Human resource development

\begin{tabular}{|r|r|r|r|r|r|}
\hline \multicolumn{2}{|c|}{$\begin{array}{c}\text { Product/service } \\
\text { development }\end{array}$} & \multicolumn{2}{c|}{$\begin{array}{c}\text { Operation technology } \\
\text { development }\end{array}$} & \multicolumn{2}{c|}{$\begin{array}{c}\text { Human resources } \\
\text { development }\end{array}$} \\
\hline$r$ & $p$ & $r$ & $p$ & $r$ & \multicolumn{1}{c|}{$p$} \\
\hline .428 & .000 & .331 & .006 & .266 & .683 \\
\hline .427 & .000 & .443 & .000 & .399 & .002 \\
\hline .451 & .000 & .330 & .007 & .415 & .557 \\
\hline .341 & .004 & .303 & .012 & .360 & .416 \\
\hline .600 & .000 & .599 & .000 & .677 & .003 \\
\hline .567 & .000 & .647 & .000 & .515 & .000 \\
\hline .622 & .000 & .630 & .000 & .508 & .139 \\
\hline .388 & .001 & .449 & .000 & .541 & .000 \\
\hline .578 & .000 & .536 & .000 & .510 & .010 \\
\hline .419 & .000 & .450 & .000 & .464 & .000 \\
\hline .410 & .001 & .406 & .001 & .430 & .000 \\
\hline .251 & .039 & .255 & .036 & .272 & .031 \\
\hline .265 & .029 & .388 & .001 & .277 & .445 \\
\hline .128 & .297 & .269 & .026 & .145 & .114 \\
\hline 1 & & .824 & .000 & .683 & .000 \\
\hline .824 & .000 & .600 & & .680 & .000 \\
\hline .683 & .000 & .680 & .000 & 1 & \\
\hline
\end{tabular}

\subsection{Structure of Differences in Basic Dimensions of Strategic Action Depending on Industry Sector}

The structure of the differences is checked using canonical discriminative analysis where grouping variable included company activity - industry sector, thus, there are two groups of companies (manufacturing and service), while the predictor set included summary scores on the basic dimensions of company positions. Extracted discriminative function may be considered statistically significant, with the significance level of $p=0.051$. Coefficient of canonical correlation $(R c=0.524)$ indicates medium intensity of difference between the groups under consideration. The modified SPACE analysis (consists of four dimensions: Competitive strength of the company, Financial strength of the company, Potential of industrial 
segment and External environment (in) stability) is used in the process of analysing external and internal company environment. As a basic result, by applying this method, company should get a clear picture about its strategic action, which may be defensive, competitive, conservative, or aggressive. On the selected study sample, the structure matrix provides the following results:

Table 4 Structure matrix
\begin{tabular}{|l|r|}
\hline \multicolumn{2}{|c|}{} \\
\hline Competitive strength of the company & Function \\
\hline Financial strength of the company & .958 \\
\hline Potential of industrial segment & .706 \\
\hline External environment (un)stability & .146 \\
\hline
\end{tabular}

Discriminative function has got a well-defined positive pole, while the negative pole of the function is not defined. Competitive strength dimension correlates with the function in a positive direction and very high intensity and the Company financial potential dimension correlates with it with somewhat lower intensity.

Table 5 Functions at Group centroids
\begin{tabular}{|l|r|}
\hline \multicolumn{2}{|c|}{} \\
\hline Manufacturing companies & Function \\
\hline Service companies & -.824 \\
\hline
\end{tabular}

Group centroids indicate that manufacturing companies are on the negative pole of the function and services companies are on the positive. Such position of the groups indicates that the service companies have got more expressed competitive strength and financial potential than the manufacturing companies.

\section{CONCLUSION}

The majority of the selected factors from the modified SPACE predominantly belongs to the model's basic dimension Competitive strength - CS (around 80\%), while minority (around 20\%) belongs to the model's basic dimension 'Financial strength' - FS. Factors belonging to these dimensions represent the basis for the development strategy formulation. Critical factors that derived from the implementation of modified SPACE analysis could belong exclusively to one of these two dimensions, either CS or FS.

Results of this research indicate a higher number of correlations (37) among service companies than manufacturing ones (27). Manufacturing companies differ from service ones mostly in the fact that they consider that new product development does not secure more market share (negative correlation is present). In the long term, this could cause a serious set of problems for the manufacturing companies if they continue to neglect the importance of internal development factors as vehicles for the market share increase.

The highest correlation for service companies is noticed between the following internal development factors: Product/service development and Operational technology development, while negative correlations do not occur (whereas manufacturing companies experience negative correlations).

The results indicate that manufacturing companies have lower competitive and financial capacity potential than service ones. Therefore, their aggressive strategic posture is less stable. The movement toward the aggressive posture is possible using generic strategy of overall cost leadership, or concentric diversification. Changing competitive posture requires a better financial strength of a company. Manufacturing companies with a good aggressive posture could help themselves by protecting their competitive advantage and increasing their market share. Unfortunately, the results of the research show that these companies do not show that the selected key development indicators are significant for the selected factors of organizational competitiveness. On the basis of research results, it could be assumed that manufacturing companies give more importance to the product development. Service and manufacturing companies both agree that product/service development, operational technology development, and human resources development are significant for themselves, and good values of these indicators could be reached through good level of other two key selected development indicators.

If a company wants to create a strategic plan of its future development, it could be defined on the basis of the selected critical factors of company development. Simulation of their value change could give a company an insight on possible or idealistic future level of competitiveness or strategic posture. That is the main value of the modified SPACE analysis.

One of the restrictions of this research could be the fact that the development level of the research region could have some impact on company's development, so the further, detailed analysis is necessary. Considering that a number of research studies were performed, and considering the fact that there is no precisely defined set of development factors for any industrial segment, it is necessary to make a further research with more countries and more development factors. Also, it is significant to further analyse the implementation of the tested strategic planning model, especially regarding its specificities, similarities and differences, while recognizing the environmental factors in doing business, that is, the regional perspective with special attention to the Republic of Croatia. Process of the integration of the Republic of Croatia in the European Union is an excellent model for other regional countries, which is substantiated by numerous bilateral agreements between countries. Although these countries are different by certain parameters, to some extent, the three countries, based on the examples of the good practice how the Republic of Croatia has enhanced their competitiveness, supported companies to achieve and maintain their competitive advantage, both on the domestic and regional markets. Cooperation between the Republic of Croatia and regional countries is important for their EU accession process. Such cooperation is also important for the Republic of Croatia, thus making a positive impact on the European integration processes development.

\section{Acknowledgement}

The authors acknowledge the financial support of the Ministry of Education, Science and Technological Development of the Republic of Serbia, within Project No 47005. 


\section{REFERENCES}

[1] Bain's \& Company. (2015). Boston - results of a research: Management tools and trends. USA

[2] Benson, A. \& Henderson, S. (2005). UK leisure centres under best value: a strategic analysis. International Journal of Public Sector Management, 18(3), 196-215. https://doi.org/10.1108/09513550510591515

[3] Borocki, J. (1998). Determination strategic posture of the company. Master Thesis, University of Novi Sad, Faculty of Technical Sciences, Novi Sad.

[4] Borocki, J. (2009). Developing strategic planning model in function of company's innovativeness. PhD Thesis, University of Novi Sad, Faculty of Technical Science, Novi Sad

[5] Borocki, J., Cosic, I., Lalic, B., \& Maksimovic, R. (2011). Analysis of Company Development Factors in Manufacturing and Service Company: a Strategic Approach. Strojniski Vestnik - Journal of Mechanical Engineering, 57(1), 55-68. https://doi.org/10.5545/sv-jme.2010.030

[6] Chaghooshi, A. J., Rahmani, M., \& Karimi Zarchi, M. (2012). Proposing a Framework for Strategic Positioning in Tile and Ceramic Industry (Integrated Approach). Journal of American Science, 8(6), 91-99.

[7] Djellal, F., Francoz, D., Gallouj, C., Gallouj, F., \& Jacquin, Y. (2003). Revising the definition of research and development in the light of the specificities of services. Science and Public Policy, 20(6), 415-429. https://doi.org/10.3152/147154303781780227

[8] Djuric, Z., Maksimovic, R., Adamovic, Z., (2010). Key performance indicators in a joint-stock company. African Journal of Business Management, 4(6), 890-902.

[9] Ettlie, J. E. \& Rosenthal, S. R. (2011). Service versus Manufacturing Innovation. Journal of Product Innovation Management, Product Development and Management Association, 28, 285-299. https://doi.org/10.1111/j.1540-5885.2011.00797.x

[10] Galer, G. \& van der Heijden, K. (1992). How Planners Create Organisational Learning. Marketing Intelligence and Planning, 10(6), 5-12. https://doi.org/10.1108/02634509210018702

[11] Griffin, A. (1997). PDMA research on new product development practices: Updating trends and benchmarking best practices. Journal of Product Innovation Management, 14(6), 429-458. https://doi.org/10.1016/S0737-6782(97)00061-1

[12] Hughes, A. \& Wood, E. (2000). Rethinking innovation comparisons between manufacturing and services: The experience of CBR SME surveys in the UK. In J. S. Metcalfe, \& I. Miles (Eds.), Innovation systems in the service economy: Measurement and case study analysis, Boston, Khwer, 105-124. https://doi.org/10.1007/978-1-4615-4425-8_6

[13] Kostanjevec, T., Polajnar, A., \& Sarjas, A. (2008). Product development through Multi-Criteria Analysis, Strojniški vestnik - Journal of Mechanical Engineering, 54(11), 739750

[14] Mikić, M., Primorac, D., \& Kozina, G. (2016). Determing the link between internationalization and business performance of SMEs. Tehnički vjesnik, 23(4), 1201-1206.

[15] Miozzo, M. \& Ramirez, M. (2003). Services innovation and transformation of work: The case of UK telecommunications. New Technology, Work, and Employment, 18(1), 62-79. https://doi.org/10.1111/1468-005X.00111

[16] The National Institute of Standards and Technology (NIST), (2006). Product and Service Innovation in Small and Medium-Sized Enterprises. Smeal College of Business, The Pennsylvania State University, USA

[17] Nijssen, E. J., Hillebrand, B., Vermeulen, P. A. M., \& Kemp, R. G. M. (2006). Exploring product and service innovation similarities and differencies. International Journal of Research in Marketing, Elsevier B.V, 23, 241-251.

[18] Özdağoğlu, A. \& Güler, M. (2016). E-service quality of internet based banking using combined Fuzzy AHP and Fuzzy Topsis. Tehnički vjesnik, 23(4), 1109-1116.

[19] Popescu, N. \& Tăchiciu, L. (2006). Research and development as a determinant of services sector competitiveness. Romanian Journal of Economic Forecasting, 4/2006, 23.

[20] Prajogo, D. (2006). The relationship between innovation and business performance: A comparative study between manufacturing and service firms. Knowledge and Process Management, 13(3), 218-225. https://doi.org/10.1002/kpm.259

[21] Radas, S. \& Bozic, Lj. (2009). The Antecedents of SME Innovativeness in an Emerging Transition Economy. Technovation, 29, 438-450. https://doi.org/10.1016/j.technovation.2008.12.002

[22] Radder, L. \& Louw, L. (1998). The SPACE matrix: A Tool for calibrating competition. Long range planning, 31, 549559. https://doi.org/10.1016/S0024-6301(98)80048-4

[23] Rant, M. (2007). Differencies in adaptations between service and manufacturing firms. Journal of Faculty of Economics Rijeka, 25(2), 245-268.

[24] Rowe, J. A., Mason, O. R., Dickel, E. K., Mann, B. R., \& Mockler, J. R. (1994). Strategic Management - A Methodological Approach. $4^{\text {th }}$ Edition, Addison-Wesley Publishing Company.

[25] Safari, H., Behrooz, A., Bazargani, H., Hosein, M., \& Soleimani-Sarvestani, M. H. (2013). Proposing a Framework for Strategic Positioning Using an Integrated Method. World Applied Programming, 3(4), 150-163.

[26] Singh, A. \& Singh, V. (2009). Innovation in services: Design and management. African Journal of Business Management, 3(12), 871-878.

[27] Sirilli, G. \& Evangelista, R. (1998). Technological innovation in services and manufacturing: results from Italian surveys. Research Policy, Elsevier Science, 27, 881899. https://doi.org/10.1016/S0048-7333(98)00084-5

[28] Šikula, M. (2006). Competitiveness in the Context of Globalization. Journal of Economics (Ekonomický časopis), $10,965-982$.

[29] Zendeh, A., Aali, S., Norouzi, D., \& Atashpeykar, H. (2012). A new Approach to SPACE Matrix. International Conference on Economics and Finance Research IPEDR, IACSIT Press, Singapore, 32, 40-44.

Contact information:

Jelena BOROCKI, Associate Professor

University of Novi Sad, Faculty of Technical Sciences,

Trg Dositeja Obradovića 6, 21101 Novi Sad, Republic of Serbia

borocki@uns.ac.rs

Mladen RADIŠIĆ, Associate Professor

University of Novi Sad, Faculty of Technical Sciences

Trg Dositeja Obradovića 6, 21101 Novi Sad, Republic of Serbia

mladenr@uns.ac.rs

Ivan ŠTEFANIĆ, Full Professor

Josip Juraj Strossmayer University of Osijek

TERA TEHNOPOLIS d.0.0

Gajev trg 6, HR-31000 Osijek, Croatia

stefanic@tera.hr 